\title{
IMPACT ASSESSMENT OF ROAD INFRASTRUCTURE: A HOLISTIC APPROACH
}

\author{
YONAS Z. AYELE \\ Faculty of Engineering, Østfold University College, Norway
}

\begin{abstract}
A competitive road construction industry can provide various benefits to the society, such as designing and building road infrastructures which can cope with the ever-changing social and economic needs. Hence, in today's competitive market, construction companies have to assess the cost effectiveness of road transport projects in order to support well-informed decision-making. Proper impact assessment will result in road design that is more advanced, efficient operations and improved environmental protection. The traditional road impact assessment methodologies, however, lack the integration of the available natural resources (renewable and non-renewable), environment and relevant stakeholders during the planning phase. The central thrust of this paper is thus to propose a holistic methodology for assessing the impacts of the road projects by taking into account the available natural resources, the environment and by involving all relevant stakeholders. The paper also outlines steps to assess both monetised and non-monetised impacts. By employing the proposed steps, the advantages and disadvantages of new road networks can be identified in a methodical way.

Keywords: impact assessment, road, network, infrastructure, cost effective, cost-benefit.
\end{abstract}

\section{INTRODUCTION}

A modern road network (infrastructure) helps to achieve smooth traffic flow and is crucial for economic growth of any country. In a nutshell, road network provides the means to transport goods as well as people; and, regarded as a one of the vital infrastructure [1]. Road network is the system of interconnected roads; and, can comprise regional and local roads, highways, municipal street networks, bicycle lanes, bridges, tunnels, private roads, etc. In general, road network design and development is a function of traffic generation (through land use, spatial planning, and development attributes) and, traffic distribution; and, it comprises:

i. Route planning - to establish specific goals and criteria for road network development, by taking into account the present and future needs of the transportation systems;

ii. Design criteria - to consider a set of road standards, such as traffic requirements, environmental safety, physical environmental factor, etc.; and

iii. Design element - to define the highway alignment.

Across the world, inadequate or poorly designed and performing road networks leads to major financial and social challenges, which governments and businesses need to address [2], [3]. In broad sense, road network designs without a proper impact assessment, produces a road, which is non-resilient infrastructure; and, which is not capable to coping with the everchanging social and economic needs [4]. Hence, in road investment decisions, the relevant decision-maker often attempt to assess the negative and positive impacts of road network projects, by employing cost-benefit and cost-effectiveness analysis. The underlying objective of identifying and categorizing the costs and benefits of road design alternatives, is to map the costs, which can potentially influence the strategic investment decision.

To investigate the cost-effective road network design that have a minimal environmental footprint, two fundamental design aspects should be discussed [5]-[7]. Primarily, the analyst should explore the road design alternatives for their cost-effectiveness and efficiency, by 
ensuring the consideration of the available natural resources, environment, and relevant stakeholders. Thereafter, for minimizing the sources of uncertainties (e.g. model, parameter, and unforeseen uncertainties), during the impact assessment, the analyst should implement procedure for quantifying the uncertainties. Over the years, number of studies have been carried out, to argue these two fundamental design aspects and suggest cost-efficient road network design, see e.g. Macias and Gadziński [5], Hanley [6], Nagurney et al. [8] and Welde et al. [9]. For instance, Welde et al. [9] compared the implementation of cost-effectiveness analysis (CEA) and cost-benefit analysis (CBA), which are the two common economic evaluation methods, as tools for allocation of national public funds in the transport sector. Moreover, Macias and Gadziński [5] discussed issues of road transport networks influence on the natural environment. Furthermore, for better understanding of the environmental impacts, Nagurney et al. [8] proposed environmental impact assessment (EIA) indices for evaluating the impacts of the degradation of the capacity of the transport link in road network.

However, most of the available CEA and CBA literature deals with either the economical aspect or the environmental impact. That means that there is a lack of integration of the available natural resources, the surrounding environment, and all relevant stakeholders when assessing the impacts (monetised and non-monetised) of the road projects. Further, there is an ongoing debate regarding the capabilities of the current models, which are employed for estimating the benefits and costs the road network investment projects [4]. This is considered as a significant drawback since inadequate or poorly designed infrastructure presents major economic and social challenges. In general, the identification of the cost-effective road design involves clarifying in what way a specific design choice influences the planned project goals. Proper CEA and CBA contributes to well-informed decisions; and, will result in a road network design, which is resilient and environmentally sustainable. Furthermore, employing a proper CEA and CBA provides an understanding about the strengths as well as shortcomings of the road design alternatives; consequently, one can infer the success and failure rate of road investment projects.

Hence, the central thrust of this paper is to propose a holistic methodology for assessing the impacts of the road projects, by taking into account the available natural resources, the environment, and by involving all relevant stakeholders. The paper also outlines steps to assess both monetised and non-monetised impacts. The rest of the paper is organised as follows: Section 2 presents a problem description. Section 3 discusses the concept of CBA and CEA process. Section 4 introduces the proposed holistic methodology for assessing the impacts of the road networks. Section 5 provides the concluding remarks.

The "road network", in the context of this paper, is the urban road network, and the starting point of our discussion is assessing the overall costs and benefits of a new road network design.

\section{PROBLEM DESCRIPTION}

The problem considered here is an impact assessment problem of the road networks. Suppose we have a finite number of road network design alternatives, each with a different construction cost, maintenance and rehabilitation cost, and HSE (health, safety, and environmental) costs. The idea is to use the most suitable design alternatives with a minimum environmental footprint. However, considering the available natural resources, the environment, and the involving relevant stakeholders when assessing the CEA and CBA of road design alternatives, the analyst will be facing with a time-dependent decision making process. That means that the analyst should deal with the design optimization problem, since integrating these factors can be considered as covariates. A covariate, in the context of this 
paper, is a factor that can have an influence on the direct and indirect costs as well as the decisions of the road projects.

To optimise the effectiveness and benefit and, to determine what road design alternative will be used, the proposed holistic methodology constantly assesses the impacts of the road projects, by considering the existing natural resources, the environment, and by involving all relevant stakeholders. The proposed methodology attempt to capture the monetised and nonmonetised impacts of new road systems.

\section{GENERIC CEA AND CBA PROCESS}

As a part of strategic decision-making, assessment tools can be employed to identify the strengths and weakness of each road design alternatives. These tools are primarily designed for evaluating the technical and design suitability of the proposed project. This will help the analyst to document all impact of the planned project and, track the progress over time [10]. The most common assessment tools and methods includes CEA, CBA, socioeconomic analysis, environmental impact assessment (EIA), etc. and are often intended for investigating a particular aspects of the road networks. For instance, CEA is a systematic evaluation of the negative and positive impacts; and, compares the cost and outcomes of the proposed road design alternatives. On the other hand, the other tools aims in identifying the suitable design alternative, by integrating the various assessment techniques into the same tool and aggregate the pros and cons each alternative; see e.g. [5]-[9]. When assessing environmentally sustainable and cost-effective road project, in general, three main issues govern the final decision. Fig. 1 illustrates these three main issues, which needs to be considered while evaluating environmentally sustainable and cost-effective road project.

\subsection{Cost-benefit analysis and cost-effective analysis}

\subsubsection{Cost-benefit analysis (CBA)}

CBA, also known as benefit-cost analysis (BAC) is a form of assessment tools; and, is primarily designed to assign monetary values to all benefits and costs [11], [12]. It

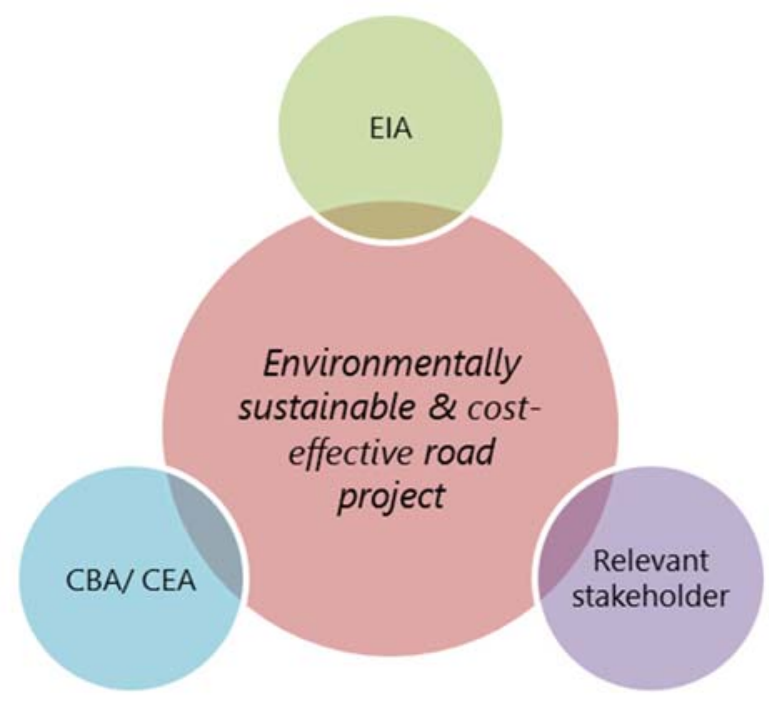

Figure 1: An overview of the relationship between the main aspects of road network. 
systematically evaluates the planed project, by identifying the strengths and weakness of road design alternatives; it is used to support qualitative arguments by providing quantitative data. CBA provides the ability to compare the cost and benefits of a specific decision; and, interested parties can outline the key issues, by providing the basis for comparing different design alternatives [13]. However, assigning monetary values to all benefits and costs will be demanding and sometimes impossible. For instance, there are intangible cost and benefits of any given road design alternatives, and, therefore, difficult to assign the monetary value. Furthermore, the choice of the discount rate directly affects the estimated results from CBA; and, unforeseen cost and benefits cannot be conceived, much less measured [13].

\subsubsection{Cost-effectiveness analysis (CEA)}

CEA is a systematic analysis tool, which evaluates and compares the relative advantage and disadvantage of various road design alternatives. In terms of the objects for analysis, the focus of the CEA is very broad for the purposes of detecting broad tendencies. This makes it ideal to employ CEA where it may be unsuitable to monetize the effect of any specific decision. Fig. 2 illustrates the key steps in the CEA; and, the underlying objectives of CEA can be categorised into three:

i. Exploring and identifying the potential key cost variables, which has a direct or indirect impact on the result of the cost-effectiveness of the selected road design alternatives.

ii. This comprises evaluating the internal and external cost variables. Internal cost variables are mainly dependent on the company's goals and criteria; and, they are particularly, managed or changed by the company.

iii. On the other hand, the company cannot manage the external cost variables; however, these variables can have direct or indirect impact on the overall cost picture.

iv. Investigating, categorizing, and profiling the sources of the planned road project risk, whether inherent or not, and company's choices regarding the acceptable risk tolerance.

v. Understanding the interdependence between estimated risk and cost variables.

vi. This means that maintaining the balance between the risk, the cost, and the benefit of the planned road project, and carefully assessing the potential advantage against potential negative impacts to operational stability.

The concept of CEA is employed during the planning process for assessing the costs on achieving the intended goals of the project as well as the best way of achieving the goals [11], [14]. The main difference between CEA and CBA is the later assigns a monetary value to all benefits and costs [11], [12]. That means that CEA is most suitable when monetized effect of a specific decision is inappropriate or when analysts face constraints for carrying out CBA [14], [15]. For example, sometimes it may be inappropriate or unnecessary to monetize the positive and negative health and environmental effects of a given alternative. CEA often perceived as a simple tool; however, there are various parameters, which could potentially alter the estimated results. Some of these parameters are the scope of the cost variables, ranges of units of measurement, prices to be included, etc. [16].

\subsubsection{Cost-effectiveness ratio (CER)}

In most cases, the result of CEA is described in terms of a ratio, which is described as a costeffectiveness ratio (CER). Typically, the CER is expressed as in terms of a ratio where the denominator is the unit of effectiveness (such as level of service of the road, number of reduced traffic accident, etc.) and, the numerator, on the other hand, is the present or 


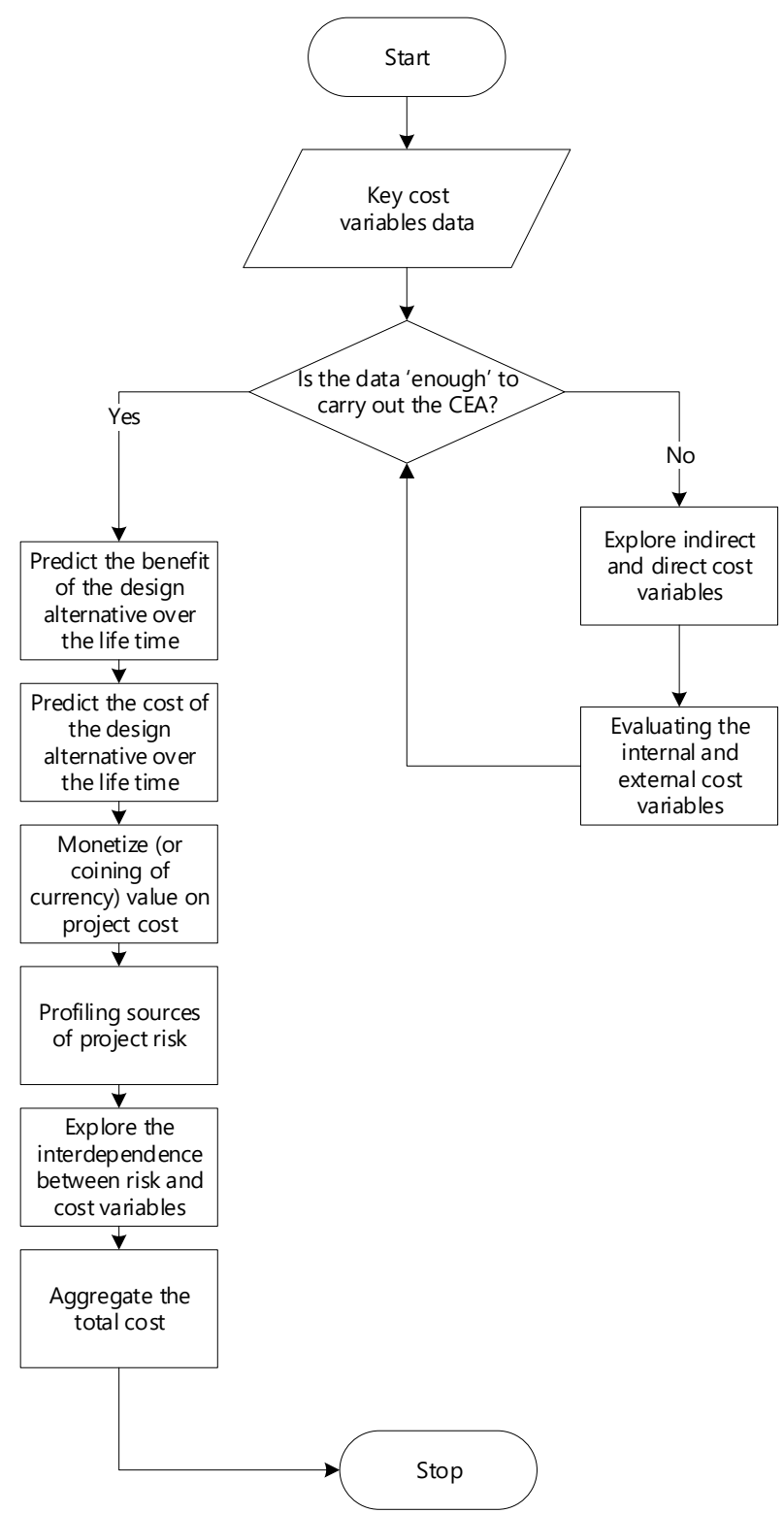

Figure 2: Fundamental steps for cost-effectiveness analysis of road design alternatives.

"discounted" value of the cost of a specific road infrastructure. In general, the unit of effectiveness is a measure of any quantifiable outcome essential to the road design objectives. In the context of road construction, the total volume of construction material required, level of service of the road, number of reduced traffic accident, etc. can be used as a unit of effectiveness.

Mathematically, CER for a specific road infrastructure, based on Cellini and Kee [17], can be described as: 


$$
C E R_{R I n f .}=\frac{P V C_{R I n f}}{U_{R I n f .}},
$$

where:

- $U_{R I n f}$ is the unit of effectiveness of road infrastructure $(R \operatorname{Inf}$.$) , and$

- $P V C_{R I n f}$. is the present value of cost of road infrastructure (RInf.), and is given by:

$$
P V C_{R I n f}=T C_{R I n f_{\cdot 1}}+\frac{T C_{R I n f \cdot 2}}{(1+r)^{1}}+\frac{T C_{R I n f \cdot 3}}{(1+r)^{2}}+\cdots+\frac{T C_{R I n f \cdot t}}{(1+r)^{t-1}}=\sum_{t-1}^{T} \frac{T C_{R I n f \cdot t}}{(1+r)^{t-1}},
$$

where:

- $T C_{R I n f \cdot 1}$ is the annualised total cost of road infrastructure (RInf.),

- $t$ represents the year from 1 to $T$ (the last year of the analysis), and

- $r$ is the discount rate.

The discount or "interest" rate, in general, shows favouring of society consumption today over consumption in the future or reflect society's lack of patience. It also affects the CER results significantly; therefore, choosing the suitable discount rate is crucial; see e.g. Cellini and Kee [17], Stern [18] and Lopez [19].

\subsection{Environmental Impact Assessment (EIA)}

EIA is an important part of road planning process; and, it involves the assessment of environmental implication of each road design alternatives. The underlying objective of EIA is to ensure that the analyst considers the negative and positive environmental consequences when deciding whether to proceed with the specific road project or not. In general, EIA comprises investigating the environmental conditions of the project area and, identifying suitable impact reduction and mitigation measures. Furthermore, a proper EIA can help to minimize the costs of a given project in the long term [20]. However, there is a continuous and considerable debate regarding the actual value and success of EIA, due to the lack of evidence, which confirms the benefit of EIA [11], [20]. Furthermore, the other argument against EIA is, the procedure is data-intensive, too complicated and complex, and the result are somehow generalized [11], [14], [20].

\subsection{Engaging relevant stakeholders}

As a principle, any impact assessment needs to ensure the involvement of all relevant stakeholders during decision-making process [21]. In general, for any given road project, in the first stages, the key stakeholders should be identified and should be involved in the decision-making process. The stakeholder could be the representative of the public, authorities, a group of environmentalist, etc., which has a special interest or concern in the intended road project plan [14], [21]. In principle, stakeholders should agree on certain prerequisites prior to commencing any impact analysis, for any road project. In addition, the analysis should also ensure that the social needs and intergenerational equity are taken into account, in all assessment stages.

\section{PROPOSED HOLISTIC METHODOLOGY}

The main steps for assessing the impacts of the road project is depicted in Fig. 3. The proposed methodology has various key elements; and, it takes into account the available natural resources, the environment, and relevant stakeholders. The first stage, in the proposed methodology, is to specify the goals and criteria based on the available standards, regulations, and recommended guidelines. The fundamental criteria is that the result from the assessment 


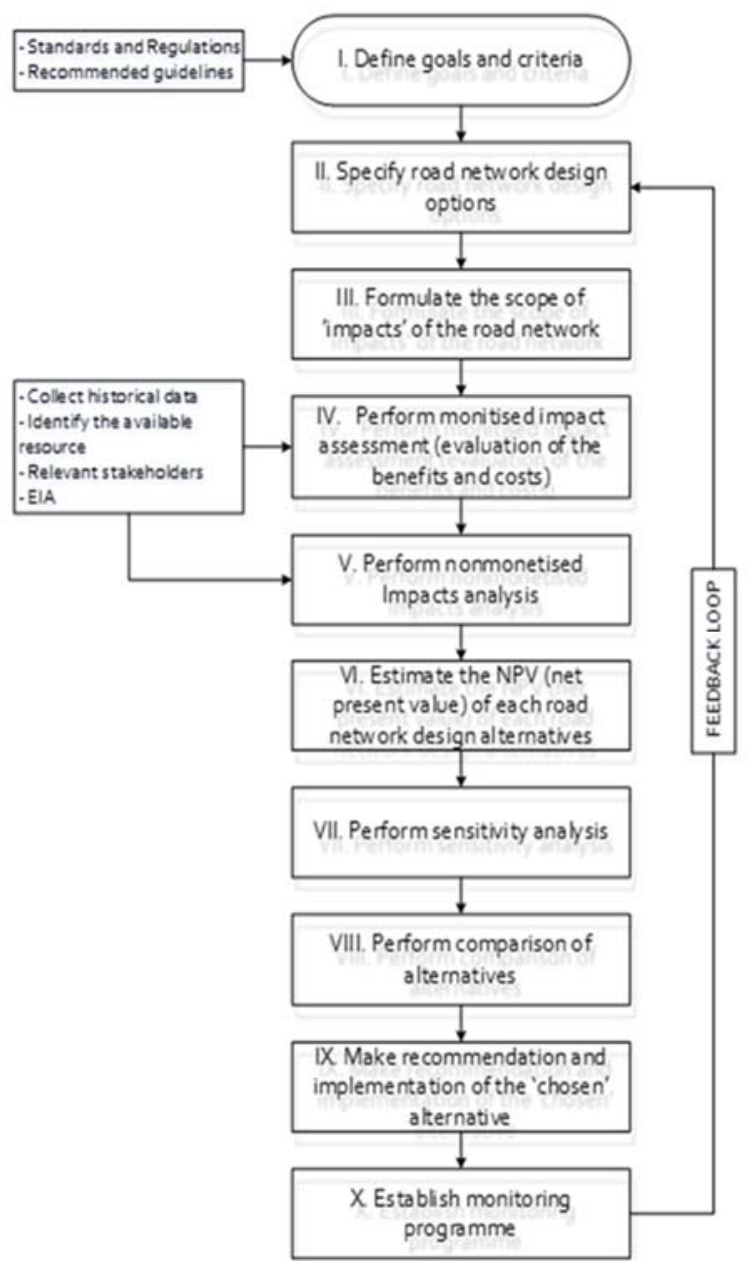

Figure 3: The proposed holistic methodology for assessing the impact of the road infrastructure.

should support the decision-maker, by clearly identifying the consequences of the chosen road design alternative. Moreover, when defining goals for effective and environmentally sustainable road network design, the inclusion of all relevant stakeholders must be ensured.

After defining the objectives, the goals, and the criteria, in the next stage, the road design alternatives should be specified. In this stage, the aspects of road network design as well as the features of transport network expansion capacity should be outlined. The road network design, in general, deeds with the configuration of network to achieve specified objectives [22]. Further, there are two variations to the design problem, the continuous network design and the discrete network design. Some of the design problem include, determining the width of the road, setting of road user charges, calculation of signal timings, etc. [22].

Formulating the scope of the impacts of the road network is the next stage. In this stage, it is essential to identify the scope of the impacts, such as the influence of the road networks in the landscape ecology. In broad sense, with construction of road networks, the range of 
human activities also increases, which amplifies human induced negative impacts on the natural ecology. Hence, in this stage, the scope should be clearly defined the facet of the impact analysis.

In the next stage, the monetized impact assessment or evaluation of the benefit and cost of the alternatives should be carried out. Further, all direct and indirect cost factors and implications should be included in the assessment. Fig. 4 depicts the key parameters that needs to be quantified. In this stage, the analyst assigns monetary values to all benefits and costs. Further, as mentioned above, the assigned discount rate affects the CBA results; thus, the analyst should be vigilant while aggregating the benefit and cost. It is also important to note that some future benefits and costs cannot conceived, much less measured [13].

After assessing and quantifying the impact, thereafter, non-monetised impact assessment should be performed. In this stage, the main emphases are on assessing the costs on achieving the goals of the network design and, the most efficient way of achieving it. Here, it is not necessary to quantify (or monetize) the benefit of achieving the intended goals. This stage is most useful when analysts face constraints which prevent them from conducting monetized impact analysis [15]. For instance, in some cases, the analyst will be facing difficulties when trying to monetise some benefits; and, this is regarded as a common constraint.

The next stage, in the proposed methodology, is estimating the net present value (NPV) of each road network design alternatives. Here, by employing the NPV method, the benefit and cost of a given road design alternative over a defined timeline should be estimated; and, thereafter, should be discounted based on the chosen discount rate to predict the aggregated

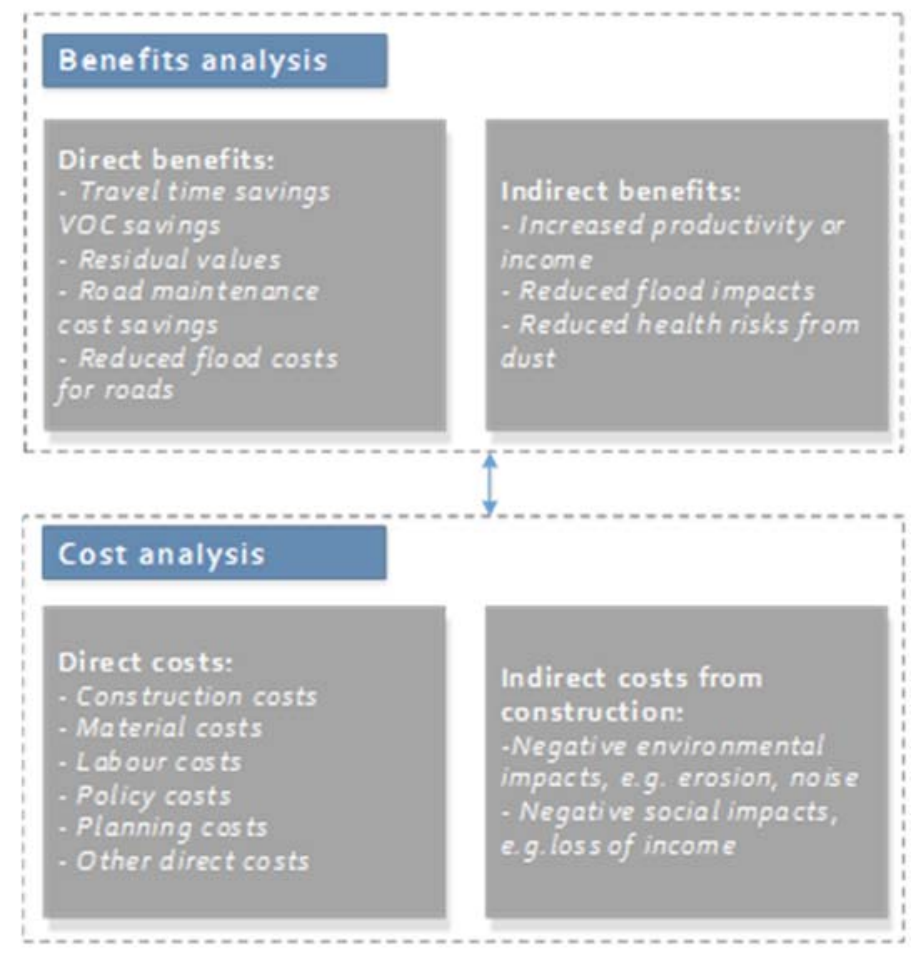

Figure 4: Monetized impact assessment: Benefit and cost analysis, modified from Systematics [4]. 
present value [23]. When aggregating the NPV, in general, one should consider the cost as negative aspect and the benefit as a positive aspect [23]. In broad, any road design with positive NPV is treated as acceptable; and, in comparing more than one design alternatives, an alternative with higher NPV should be accepted.

After estimating the NPV for each alternative, in the next stage, the sensitivity analysis should be performed. The fundamental objective of sensitivity analysis is to investigate the key cost variables as well as their effects on the annualized total cost and aggregated present value cost. In general, there are two types sensitivity analysis - partial and extreme case sensitivity analysis. In principle, partial sensitivity analysis involves varying one key assumption or cost variable at a given time, and keeping the other assumptions or cost variables constant [17]. Contrary, the extreme approach involves varying all uncertain variables at the same time, and selecting the values for each variables, which yields either the worst- or the best-case scenario [17], [24].

Thereafter, the comparison between the alternative design options should be performed. The comparison should consider the strengths and weaknesses of each alternative, check the extent and the validity of the "results" obtained from the assessment, and investigate whether a given design alternative match the intended plan and outcomes, etc. Further, at this stage, specific effectiveness indicators should be clearly identified; the advantage and disadvantage of the proposed road design alternatives should be assessed; and, the implementation of the HSE standards should be ensured, by incorporating the socio-economic features.

Thereafter, the recommendation should be made and, afterwards the chosen road design alternative should be implemented. The recommendation should comply with road design standards and guidelines. Subsequently, the one should monitor the recommended results, by introducing the monitoring and surveillance program. The aim of the program is to observe as well as follow-up the implementation of the selected road design alternative. In addition, a feedback loop should be introduced, for reviewing the results from the assessment as well as the selection process of the road design alternatives.

\section{CONCLUDING REMARKS}

This work proposed a holistic methodology for assessing the impact of the road networks based on the consideration of possible road design alternatives. The methodology is mainly suitable in assessing the impacts of the new road projects since it takes into account the available natural resources, the environment, and the relevant stakeholders. The proposed methodology comprises two parts. The first part evaluates the goals and criteria aspects of the road network design; and, predicts the net present value of each road design alternatives, by categorising the road networks impact into two: monetized and non-monetized. The second part performs the sensitivity analysis, compares the road design alternatives and, consequently provides a recommendation and implementation of the best road design alternative.

The following are the main findings:

- The proposed holistic methodology is valuable as it discuss the fundamental principles and key steps of the cost-effectiveness analysis and cost-benefit analysis (benefit cost analysis) of a specific road design.

- By employing, the proposed methodology one can carefully evaluates the potential advantage against potential negative impacts to operational stability of a specific road design alternative. This consequently helps to ensure cost-effective and environmentally sustainable road infrastructure design. 
- Furthermore, the analyst can implement the outlined steps to investigate, categorize, and profile the inherent risk of a specific road design alternative; and, company's choices regarding the acceptable risk tolerance.

Our conclusion is that to address the challenges related with inadequate or poorly designed and performing road infrastructures, a proper impact assessment of road design alternatives is vital. Hence, employing the proposed holistic methodology can have significant effects on achieving the socio-economic and HSE goals; by investigating the key cost variables as well as their effects on the annualized total cost and aggregated present value cost of any road project.

\section{REFERENCES}

[1] Anor, N., Ahmad, Z., Abdullah, J. \& Hafizah, R.N., Road network system in Port Klang, Malaysia and impacts to travel patterns. Procedia-Social and Behavioral Sciences, 35, pp. 629-636, 2012. DOI: 10.1016/j.sbspro.2012.02.130.

[2] Dobbs, R., Pohl, H. \& Lin, D., (eds), Infrastructure Productivity: How to Save \$1 Trillion a Year, McKinsey Global Institute, 2013.

[3] Ayele, Y.Z., Barabadi, A. \& Markeset, T., Spare part transportation management in high North. Proceedings of the 22nd International Conference on Port and Ocean Engineering under Arctic Conditions (POAC), 2013.

[4] Rahman, A.S., Dowell, P., Sallman, D. \& Dzakwasi, E., (eds), Norwegian Road Network Strategic Assessment: Re-examining the Estimation of Costs and Benefits of Investments in Road Transport in Norway, Cambridge Systematics, Inc., 2012.

[5] Macias, A. \& Gadziński, J., Assessment of road transport environmental impact as illustrated by a metropolitan area. Polish Journal of Environmental Studies, 22(6), pp. 1749-1758, 2013.

[6] Hanley, N., Cost-benefit analysis and environmental policymaking. Environment and Planning C: Government and Policy, 19(1), pp. 103-118, 2001.

[7] Ayele, Y.Z., Barabadi, A. \& Barabady, J., Dynamic spare parts transportation model for Arctic production facility. International Journal of System Assurance Engineering and Management, 7(1), pp. 84-98, 2016. DOI: 10.1007/s13198-015-0379-x.

[8] Nagurney, A., Qiang, Q. \& Nagurney, L.S., Environmental impact assessment of transportation networks with degradable links in an era of climate change. International Journal of Sustainable Transportation, 4(3), pp. 154-171, 2010. DOI: 10.1080/15568310802627328.

[9] Welde, M., Eliasson, J., Odeck, J. \& Börjesson, M., The use of cost-benefit analyses in Norway and Sweden: A comparison. Proceeding of the European Transport Conference, 2013.

[10] Zurbrügg, C., Caniato, M. \& Vaccari, M., How assessment methods can support solid waste management in developing countries - a critical review. Sustainability, 6(2), pp. 545-570, 2014. DOI: 10.3390/su6020545.

[11] Finnveden, G., Björklund, A., Moberg, Å. \& Ekvall, T., Environmental and economic assessment methods for waste management decision-support: possibilities and limitations. Waste Management \& Research, 25(3), pp. 263-269, 2007. DOI: 10.1177/0734242x07079156.

[12] Skovgaard, M., Ibenholt, K. \& Ekvall, T., Nordic guideline for cost-benefit analysis of waste management. Nordic Council of Ministers, 2007. 
[13] Shively, G. \& Galopin, M., An overview of benefit-cost analysis. Online. www.agecon.purdue.edu/staff/shively/COURSES/AGEC406/reviews/bca.htm.

Accessed on: 20 Apr. 2014.

[14] Ayele, Y.Z., Barabadi, A. \& Barabady, J., Effectiveness assessment for waste management decision-support in the Arctic drilling. Proceedings of the IEEE International Conference on Industrial Engineering and Engineering Management (IEEM), pp. 559-564, 2014.

[15] WHO, Making choices in health: who guide to cost-effectiveness analysis. Online. www.who.int/choice/publications/p_2003_generalised_cea.pdf. Accessed on: 20 Apr. 2018.

[16] Priorities in Health: Chapter 3 cost-effectiveness analysis. Online. www.ncbi.nlm.nih.gov/books/NBK10253/. Accessed on: 20 Apr. 2018.

[17] Cellini, S.R. \& Kee, J.E., Cost-effectiveness and cost-benefit analysis. Handbook of Practical Program Evaluation, pp. 493, 2010.

[18] Stern, N.H., The Economics of Climate Change, HM Treasury: London, 2006.

[19] Lopez, H., The Social Discount Rate: Estimates For Nine Latin American Countries, World Bank Policy Research Working Paper Series, 2008.

[20] Jonathan, R. \& Emma, J., Environmental impact assessment tools and techniques. Online. http://green-recovery.org/wordpress/wp-content/uploads/2010/11/Module-3Content-Paper.pdf. Accessed on: 20 Apr. 2018.

[21] Morrissey, A.J. \& Browne, J., Waste management models and their application to sustainable waste management. Waste Management, 24(3), pp. 297-308, 2004. DOI: 10.1016/j.wasman.2003.09.005.

[22] Tom, V.M. \& Mohan, S., Transit route network design using frequency coded genetic algorithm. Journal of Transportation Engineering, 129(2), pp. 186-195, 2003. DOI: 10.1061/(asce)0733-947x(2003)129:2(186).

[23] Sinha, K.C. \& Labi, S., Transportation Decision Making: Principles of Project Evaluation and Programming, John Wiley \& Sons, 2011.

[24] Ayele, Y.Z., Barabadi, A. \& Droguett, E.L., Risk-based cost-effectiveness analysis of waste handling practices in the arctic drilling operation. Journal of Offshore Mechanics and Arctic Engineering, 138(3), p. 031301, 2016. DOI: 10.1115/1.4032707. 